\title{
Analysis of facial expression movements and the phenomenon of frontal asymmetry as the basis for automation of the research of hidden cognitive attitudes. Some basic remarks
}

\author{
Krzysztof Sołoducha*
}

\begin{abstract}
The aim of this text is to show how, using the achievements of modern computer science, psychology and neurobiology, we can search for an answer to the question about the a priori mechanisms of shaping a phenomenal image of reality given by experience. This phenomenalism statement is very close to, so called, Bayesian model of mind by Karl Friesen. The author asks how in massive scale to reach the cognitive processes taking place without representation, outside the field of consciousness, which influence the formation of this model of the world. The result of the consideration is to be a neuromachine project whose task will be to automate and mass research of hidden cognitive attitudes. Its activity is to become a real alternative to opinion polls performed in the paradigm of the so-called declarative sociology, which do not provide results significantly reducing the risk of decision-making in management.
\end{abstract}

Keywords: hidden cognitive attitudes, analysis of facial expression movements, frontal asymmetry effect, phenomenalism.

\section{Introduction}

The dynamically developing philosophy of computer science in recent years [29] is based on the programme proposed by the Vienna Circle and often propagated as a modern way of defining the role of philosophy in the system of knowledge. According to this programme philosophy should give up its own cognitive ambitions and questions.

Instead, philosophy should focus, on the one hand, on generalizing the results of sciences, building a general worldview based on their results, and, on the other hand, on researching

\footnotetext{
* Military University of Technology in Warsaw, Krzysztof.Soloducha@wat.edu.pl
} 
the foundations of these sciences, analyzing basic concepts, building their methodological and epistemological models, i.e. it should offer a kind of "service" for the scientistic and naturalistic model on which modern natural sciences and computer science is founded.

In such a model, the philosophy of computer science is similar to the philosophy of technology, the philosophy of religion, or the philosophy of law. And in this role she acts as an assistant for the development of these specific disciplines, taking care of their epistemological correctness and methodological purity. But this does not seem to be the only possible way to define the relationship between philosophy and computer science.

Another approach, close to the author, could be rather to look for an answer to the question of how the achievements of contemporary computer science can be used to search for answers to classical philosophical questions. It is an approach close to a modern program of using the achievements of computer science in modern humanities - digital humanities [1, 23].

One of classical philosophical questions is the problem concerning passive synthesis and phenomenalism - that is, the question of objectivity as given and founded only in the experience of the subjects. Immanuel Kant is considered as the creator of the phenomenalism programme, and its most important followers was, of course, the phenomenological school. Both Kant's and the phenomenological research programmes were aimed at discovering the subjective, apriorical elements of all objectivity. Thanks to pointing out the basics of all possible experiences phenomenalism is a solution to basic philosophical problems, such as the problem of the possibilities of synthetic judgments a priori or anti-psychologism in the philosophy of mathematics. Despite of the "cognitivist turn", the demands of the classical theory of cognition have remained valid.

The aim of this text is to show how, using the achievements of modern computer science, psychology and neurobiology, we can search for an answer to the question about the a priori mechanisms of shaping a phenomenal model of reality given by experience. The author asks how in massive scale to reach the cognitive processes taking place without representation, outside the field of consciousness, which influence the formation of this model of reality. The importance of answering this question is very high so far as, on the basis of these unconscious cognitive processes, decisions are made which not only have an adaptation function, but are also initiated as management processes, through which we set ourselves goals, and then plan and implement actions aimed at achieving them [18, 9].

In this way, we will indirectly consider the problem of whether the ancient faith in reason has its theoretical basis today, and whether the man who acts and makes decisions is a rational being.

\section{Passive synthesis and phenomenalism}

The approach we represent is based on the concept of passive synthesis as the founding term for the philosophical program of phenomenalism [24].

Its creation is attributed primarily to the authors of the modern programme of cognition theory, in which the traditional epistemological issues were reinterpreted. According to the 
approach proposed by Descartes and his followers, it is the analysis of the very medium of the emergence of knowledge, of the subject of cognition, that should allow the solution of the epistemological problem of its true status. And since, according to Francis Bacon's programme, the most important task of knowledge is to build a "New Atlantis" - a paradise on earth here and now based on the achievements of empirical knowledge transformed into technology, this problem of truth is not only a theoretical issue, but a practical challenge to ensure the realization of the ancient ideal arete - a courage based on the effective transformation of knowledge into action. In the age of mathematical natural science it is possible thanks to the opportunity to build synthetic judgments a priori [22]. A constant challenge for the theory of knowledge to this day is the question about the conditions for the possibility of the creation of such a theoretical natural science [11].

We owe the precise formulation of this problem to Immanuel Kant, according to whom apriorically built knowledge of experience is possible thanks to the very status of experience, which is always someone's. Therefore, all possible experience is possible thanks to the mixing of data from the dark sphere of noumens with a priori categories of sensuality and intellect.

This standpoint is based on the idea that the so-called world of all possible experiences is the domain of passive syntheses, and that all objects are created by a mixture of sensual data and a priori categories that partly takes place without representation in conscious.

This mixing is a basic knowledge-generating process, thanks to which objects are created that are a combination of passively received data with categories that organize them. This activist approach to epistemological problems allows us to answer the question of the possibility of creating a priori synthetic judgments. This view, later called phenomenalism, became the foundation for the whole nineteenth-century theory of cognition. It is in fact the only, reasonable, non-creationalistic explanation of the possibility of the existence of theoretical, modern natural science and its practical successes.

The phenomenological school, on the other hand, was based on the idea of reduction, which, although it provided an answer to the question of intersubjectivity through the concept of a transcendental subject, immersed phenomenology in the problem of material and nonmaterial apriori and the method of reaching out to supernultural and timeless phenomenological beings. Phenomenology is also burdened with allegations of sylophobia and platoonism. Husserl has tried for years to solve these dilemmas by introducing the concept of Lebenswelt and by gradually moving from the concept of a transcendent subject to that of an empirical subject. It ended with the concept of morphology as a pathway for the analysis of a priori of empirical formation [16].

\section{New impulse for phenomenalism}

New impulse for development of phenomenalism has been provided by the results of current brain research and in particular by the introduction of fluorescence microscopy in recent years, which enables brain mapping to a depth of $10 \mathrm{~cm}$ without the need for plastering, as is the case of fMRI [2]. 
Research using fluorescence microscopy carried out on small brains, e.g. mice or opuses, shows that giving a stimulus not only causes modular activation, as evolutionary psychologists would like, but also stimulates entire cognitive structures.

The modules, which are directly receptive, stimulated and reactive to external impulses, are accompanied by reactions of the whole cognitive sphere, supplementing the data collected from the immediate environment with those elements which are necessary for the efficient implementation of the adaptation process. Of course, the crown argument in favour of this thesis is the phenomenon of phantom pains and the medical problem of eliminating them [http://www.braininitiative.org, access 03.11.2018].

These new results could suggest that the basic activity of the cognitive system is to build a model (or system of models) of reality in which even the slightest change in its peripheries causes modification of the whole image of the world on the basis of which cognitive behaviours are realized. The theory of Karl Friston's deals with this issue. According to this:

perception as a constructive process based on internal or generative models. The underlying idea is that the brain has a model of the world that it tries to optimize using sensory inputs [8].

In accordance with the principle of minimum potential energy concerning physical systems in nature, the model of reality serves us to minimize our efforts. Every change requires thermodynamically large west, plasticity, sometimes creating a new model. It is a predictive top down model which is based on basic thermodynamic idea of minimisation of entropy - so called Bayesian model of mind.

This hypothesis, which is supported by wide-ranging scientific discussion [4], will underpin our deliberations. We consider it to be a bridge between the above philosophical considerations and the neuromachine project, which is to be a solution to the philosophical problem of passive synthesis.

Important assumption to which we will refer is the paradigm of the embodied mind, as one of the three (four) basic paradigms of contemporary cognitive science. In accordance with its assumptions presented in the most important studies the cognitive system is created in direct correlation with the environment mediated by the body, and in this respect there is a direct relationship between measurable bodily phenomena and the processes of passive synthesis occurring in the cognitive sphere, partly without representation in consciousness $[21,32]$.

\section{Measuring body phenomena and studying hidden cognitive attitudes}

The development of cognitive science, neurobiology and psychological research is currently allowing the study of cognitive processes that are not represented in consciousness. The classic research techniques include fMRI - magnetic resonance, fluorescence microscopy, EEG, skin conductivity examination and mimic expression examination. All these methods have their technical characteristics and limitations. Let's have a look at some of the features of selected methods. 
The fMRI scanner monitors the blood flow in the brain to the neurons that are involved in the workflow. The metabolic processes of the brain, i.e. its energy management, so called BOLD signal [14], are analysed. In such studies it is assumed that the more blood is taken from the brain and the more glucose is burned, the harder it works. This made it possible to create a graphical representation of the presentation of what is happening in the brain processing information, stimuli or performing certain mental processes. Compared to others by techniques is the most expensive, slowest and least handy test in use. The problem of fmri research is so called slicing, which does not allow insight into the activity of whole brains in real time. These limitations forced the emergence of other imaging techniques, such as fluorescence microscopy, which does not have these limits.

Fluorescence microscopy is a technique of research of mind activity which allows to follow brain activity in, so called, in vivo mode. Especially technology called SPIM (single plane illumination microscopy). Advantages of SPIM microscopy is that the exposure time is comparable to a single exposure time nerve impulse (about $1 \mathrm{~ms}-100 \mathrm{~ms}$ ). Device of this type is able to illustrate within a few milliseconds of the entire frame, e.g. a selected part of the brain, not as in the case of confocal or twophotone microscopy [19].

The EEG test involves the appropriate distribution of electrodes on the skin surface, which record the changes in electrical potential on the skin surface from the activity of the cerebral cortex neurons and, after appropriate strengthening, they form a notation. The biggest advantage of the EEG study is its low cost and easiness of implementation. Small data streams generated during the study are equally important. Portable devices are also available for easy signal detection. The problem of EEG tests is high signal noise and its individual specificity, which makes interpretation of signal difficult.

Despite of features listed above, two important criteria of choice the method of study of cognitive processes that are not represented in consciousness we have to consider for the purpose of our deliberations.

Firstly, it is a technical feasibility that can go beyond the laboratory sphere, and secondly, it is a predictive power that allows the paradigm of declarative sociology to be replaced in research. On the other hand, the techniques considered should be natural, networkable, the data streams generated by the survey should be transferable over an ICT network, the data should be easy to handle mathematically and to develop machine learning procedures, and the techniques for data aggregation should be low cost and easy to implement. Of the testing techniques listed above, only two currently appear to satisfy these criteria adequately. It is a technique of EEG (Electroencephalography) research and a technique of mimic facial movements research.

With EEG research there is a phenomenon of high signal noise and difficulties with data interpretation, therefore in order to carry out this part of the study and to minimize the costs of the apparatus it is necessary to base the system on a phenomenon that will simplify the interpretation and reduce the costs of conducting the research. This is a widely described in literature phenomenon of frontal asymmetry. For facial expressions, on the other hand, the Faces Movement Encoding System (FACS) invented by Paul Ekman and his followers can be used as the basis. 


\section{Frontal asymmetry effect}

Human cognitive systems are electrical machines whose side effects are electromagnetic waves generated in the frequency range of $1-100 \mathrm{~Hz}$ and amplitude from 5 to several hundred $\mathrm{mV}$, which can be measured by using specialized devices and software. The measurement is based on the recording with 16 or 24 electrodes of the electrical potential changes on the skin surface resulting from the activity of brain nerve cells. Once they have been strengthened, a record is created. This research method was invented by Adolf Beck, one of the first Polish neurophysiologists. The first human research was carried out by a German psychiatrist Hans Berger in 1924.

The frequencies of the recorded brain waves are signed by the letters of the Greek alphabet from alpha to theta. The appropriate wavelength frequency is correlated with the type of cognitive activity performed. There are basic correlation schemes, but in the field of higher cognitive activities, the EEG recordings are very specific, which makes them difficult to use for the registration of complex cognitive processes like decision making for instance.

However, there are some stable and reproducible correlation schemes between the recorded EEG signal and higher cognitive activities, which can be used to detect hidden, not represented in the consciousness higher cognitive attitudes and which also meet the technical requirements of the planned system.

For our purposes, it seems most correct to use the effect of frontal asymmetry, which was observed more than 70 years ago when monitoring the lesion in the frontal cortex. Wide literature on this issue has evolved from the search for an emotional connection between the recording of asymmetrical brain wave activities in the left or right cortex to the abandonment of the emotional paradigm in favour of the motivational one [10].

In this sense, the EEG activation of the left anterior frontal cortex indicates a positive motivation (approach motivation), and activation of the right side of the frontal cortex a negative motivation (withdrawal motivation). This motivation is not clearly correlated with positive or negative emotions, as was assumed in the early stage of research on the effect of frontal asymmetry.

Seven measurements use F3/F7 or F4/F8 electrodes to record beta, gamma or alpha waves. The index is most often calculated as a logarithm from the relation of left and right activity measurements. This is an index calculation method proposed by "Imotions", a company specializing in the measurement of biomedical signals in the brain. 


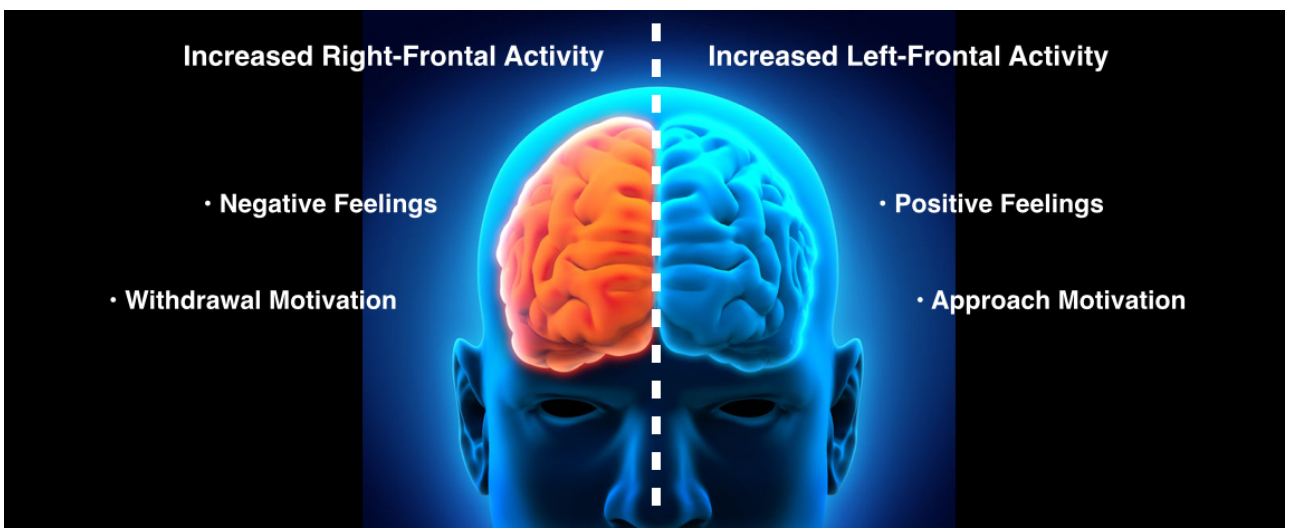

Illustration 1. Frontal asymmetry effect and correlation between increased brain activity and feelings/motivation character, source: iMotions 2017

(1) Channel Activity $(\mu \mathrm{V})$

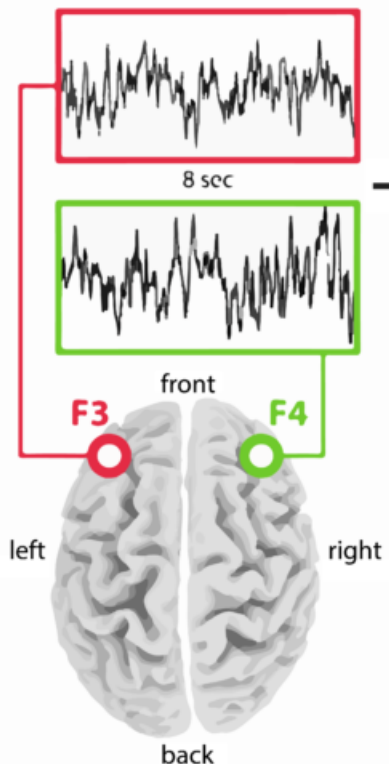

(2) Frequency Band Power $\left(\mu \mathrm{V}^{2}\right)$

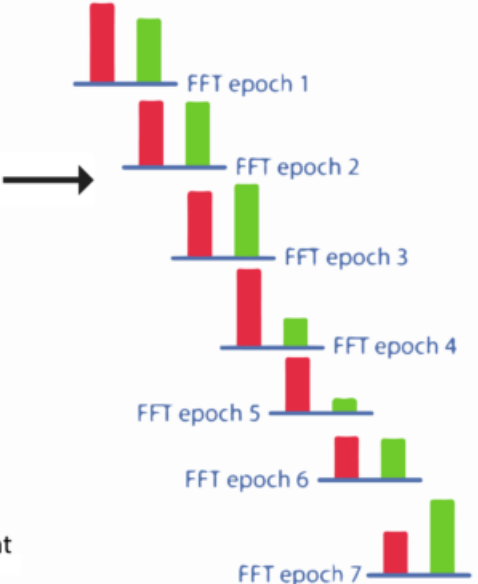

(3) Frontal Asymmetry Index
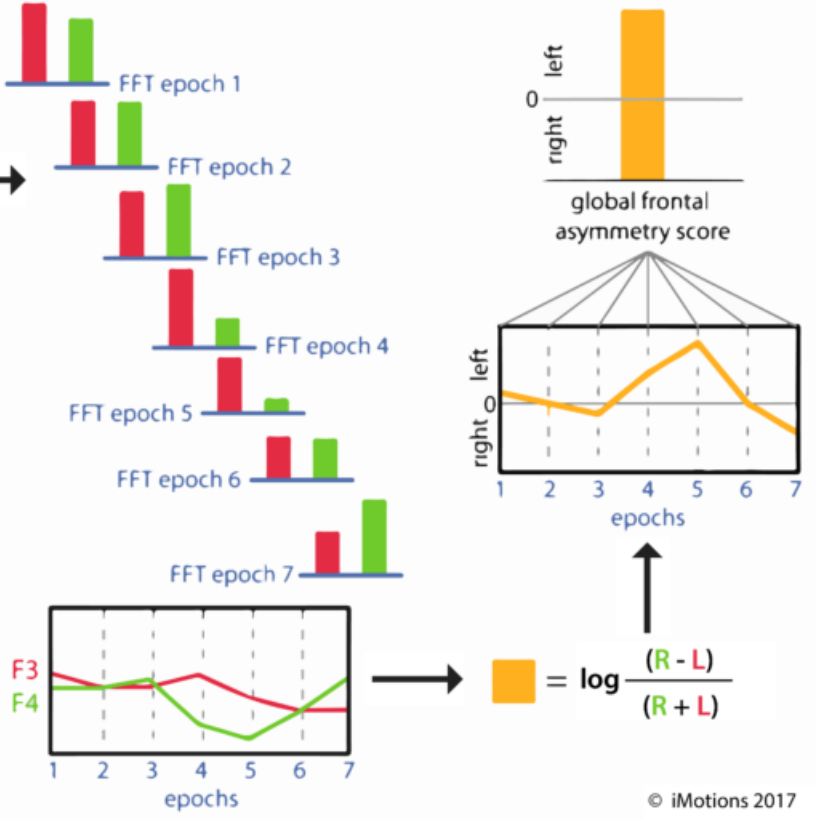

Illustration 2. Example of a method of calculating the front asymmetry index according to IMotions company, source: iMotions 2017 


\section{Facial expressions analysis}

The Facial Action Coding System (FACS), developed by P. Ekman and W. V. Friesen, (1978) is considered to be the most powerful system for interpreting facial expressions, i.e. short facial changes caused by muscular cramps. The human face contains about 80 muscles whose movements can create thousands of facial expressions. Despite individual differences in the distribution of fat tissue within the face, wrinkle constants, bone structure and muscles, mimic expressions have common patterns, independent of individual differences.

Ekman and Friesen (1978) assumed in their system that facial behavior could be described by means of the so-called Action Units or their combination (Combo). Based on their knowledge of facial muscle anatomy and mechanics, they distinguished 44 individual Units of Motion (JR). The units of movement are caused by the cramps of certain muscle groups and can be seen with the naked eye or with the help of a camera. Some muscles may work in different ways and cause different changes in the appearance of the face described in separate Units of Movement [6].

Each unit has a name and is signed with a number that serves as a code for the facial behaviour described (e.g. JR 1 - Lifting internal eyebrows). For some Units, the intensity is also determined on a seven-degree scale. The emotional significance of expression has been tested in numerous laboratories where FACS has been used. Before any interpretation was placed in the database, it was first analysed in detail. The creation of FACSAID was preceded by an evaluation of the 5,000 combinations that occurred in various empirical studies [6].

By comparing the encoded mimic expressions with the information contained in the database, their emotional significance was checked on the basis of the interpretations made so far. The designed system can use the standards contained in this database to implement automation of the mimic expression analysis and to search for correlations with the results of the positive or negative motivation analysis recorded in the EEG. To design this element of the system, it is also possible to use the already existing automatic facial and facial expression recognition systems.

\section{The problem of declarative sociology and the use of results of research on hidden components of passive syntheses}

Questionnaire research is still the basic method of researching attitudes towards selected stimuli and facts. The paradigm of declarative sociology is based on several basic beliefs that are being questioned today.

Firstly, its essence is the conviction that respondents have full access to attitudes towards a given stimulus or phenomenon, which is the subject of research. Numerous studies indicate that this is not the case. Of course, the best known research in this field is the famous experiment by Zajonc [33], but there are also many other examples in the fields of psychology, cognitive science, neurology and sociology that can be used to contest this belief, like research by Antonio Damasio for instance [5]. 
Secondly, the high costs of traditional sociological research force extreme extrapolations to be made based on the assumption of a so-called representative group. The reliability of these extrapolated data in the paradigm of declarative sociology is very limited by cultural and social factors: the basis for research must be the lack of public concern today about declaring one's attitude towards the stimulus. The rules of political correctness and the willingness to belong to the so-called reference group often prevent respondents from declaring their real political preferences in the so-called exit poll conducted during the elections. This aversion to declare real political preferences explains errors in forecasting election results. A good example is the recent local government elections in Poland. According to the data available on specialized websites, survey errors of elections In Warsaw ranged from 15,75 to 35,91 percent [sprawdzamysondaze.pl, access 31.10.2018]. The level of these errors makes rational management decisions very difficult to make.

On the other hand, difficulties in declaring preferences for the stimulus may be caused by the lack of access to this information in the respondent's cognitive system. General assumption of our deliberations is that there is a class of hidden cognitive attitudes without any possibility to be presented in consciousness.

These and other factors result in a low level of results credibility and far-reaching gaps between the declared attitudes towards the stimulus and the real behavior of respondents. Of course, when their results are used for management purposes, there is a significant level of mistrust and a need for interpretation. This limits the actual usability of the results of research conducted in the paradigm of declarative sociology. In fact, they do not sufficiently reduce the risk of management decisions, but can only be advisory or subsidiary. That is the game at stake.

The question that we would like to ask at the end is, therefore, whether at the present stage of development of research in the field of cognitive processes we have sufficient technical resources to create a method of mass and effective research of the sphere of cognitive processes not represented in consciousness.

\section{Neuromachine - a proposal of architecture}

The considerations presented above give hope for the construction of a properly functioning device which would allow for effective and representative research of hidden cognitive attitudes of the respondents and which would provide results which would effectively reduce the risk of management decisions. 


\section{$\underline{\text { Neurbiological signal analysis environment }}$}

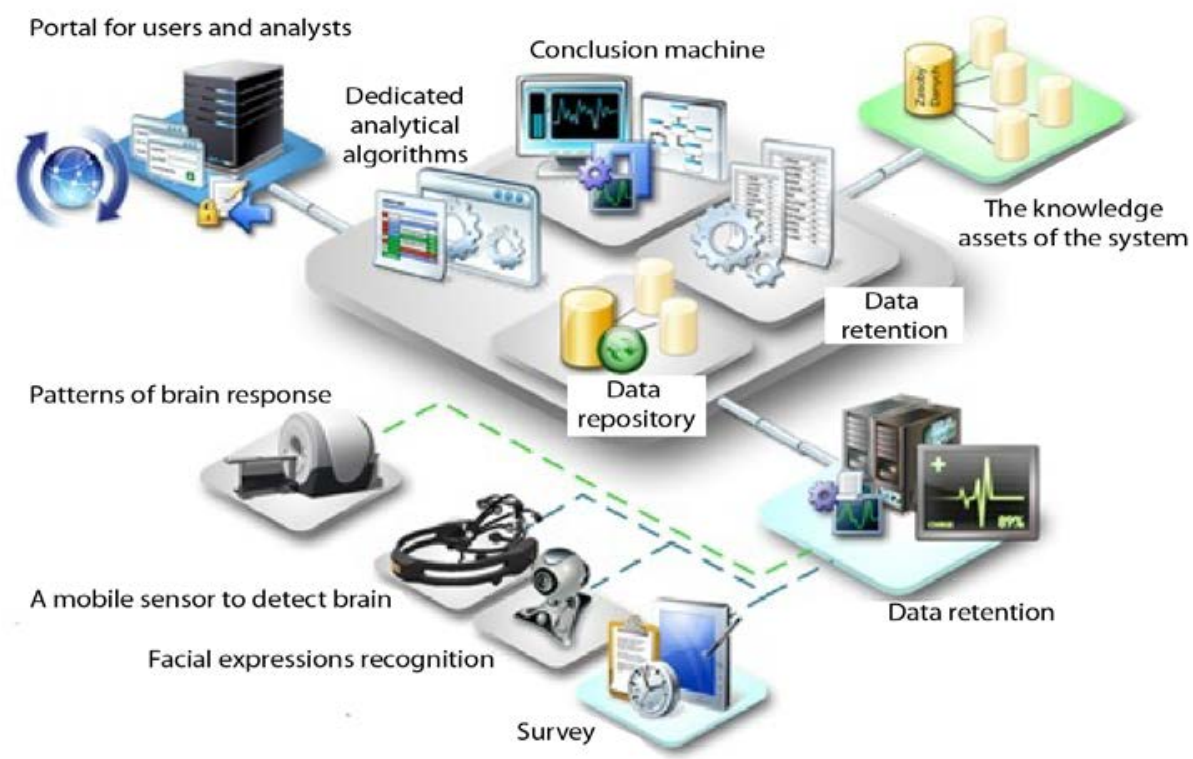

Illustration 3. Diagram of neuromachine, source: own research

The base of the machine is a mass data delivery system. The data comes from a profiled group of respondents obtained from a database built as a basis for the system. The data comes from webcams, small EEG devices and online surveys. The data is obtained from large groups of respondents gathered at the stage of building the system. Thanks to that it is possible to avoid majority of problems with extrapolation of result of research.

Fundament of the data evaluation system is a group of patterns built on the basis of magnetic resonance research - fMRI. On the basis of these patterns will be built correlations between the interpretation of EEG signals and the recorded facial expressions, sometimes enriched even by the results of surveys. The use of fMRI patterns makes it possible to improve the interpretation of survey data from EEG portable devices and cameras.

The data are transferred to the retention system from where they are transferred to data repositories which form the basis of the conclusion machine supported by advanced machine learning systems building the knowledge of the system. Large data streams and machine learning procedures will consistently improve the quality of data interpretation patterns.

The data are presented in the users' and analyst's portal, where the transaction system is also located. The research is considered as paid service with online system of target group selection 


\section{Final remarks}

Presented in this paper proposal of neuromachine should be considered as a theoretical concept that requires precise technical and mathematical elaboration by an interdisciplinary team of mathematicians, neurobiologists, sociologists, computer scientists and specialists in the reading of facial expressions. Implementation requires use of brain imaging techniques to create mathematical patterns for data processing automation and the use of the latest technique of machine learning which should allow gradual improvement of the quality of mathematical data analysis patterns. An additional element that makes it easier to work on practical implementation of above presented concept is possibility to purchasing some readymade elements of a potential system. Here can be listed elements like facial expression patterns of FACS system, simple and cheap EEG biological sensors and algorithms for automation of recognition of face expressions [34].

The system built on the basis of the above mentioned assumptions gives hope for commercial use and construction of market effective solution. The author tries to obtain funds for the implementation of above mentioned research and creating an IT system that automates the research of hidden cognitive attitudes.

\section{References}

[1] Berry D., The computational turn: Thinking about the digital humanities, Culture Machine, 2011, 1-22, http://sro.sussex.ac.uk/49813/1/BERRY_2011THE_COMPUTATIONAL_TURN_THINKING_ABOUT_THE_DIGITAL_HUMANITIES.pdf

[2] Blázquez-Castro A., Stockert J.C., Fluorescence Microscopy in Life Sciences. Bentham Science Publishers, 2017.

[3] Bowers S., Davis J., Bayesian just-so stories in psychology and neuroscience, Psychological bulletin 138 (3), 2012, 389-414. doi:10.1037/a0026450.

[4] Clark A., Whatever next? Predictive brains, situated agents, and the future of cognitive science, w: The Behavioral and brain sciences, 36 (3), 2013, 181-204. doi:10.1017/S0140525X12000477

[5] Damasio A., Błąd Kartezjusza, Poznań, 1999.

[6] Draheim, S. E., System Kodowania Ruchów Twarzy (FACS) jako metoda mierzenia zachowań mimicznych: Procedura - rzetelność - zastosowania, w: PsychologiaEtologia-Genetyka, 7, 2001, 7-44.

[7] Ekman, P., Friesen, W. V., Facial Action Coding System (FACS): A technique for the Measurement of facial actions, Consulting Psychologists Press, Palo Alto, CA, 1978.

[8] Friston K., The free-energy principle: a unified brain theory?, in: Nature Reviews Neuroscience, published 13.01.2010.

[9] Gigerenzer G., Good feelings: The Intelligence of the Unconscious, Penguin Books 2008. 
[10] Harmon- Jones E., Gable P., Peterson C., The role of asymmetric frontal cortical activity in emotion-related phenomena: A review and update, in: Biological Psychology 84, 2010, 451-462.

[11] Heller M., Jak możliwa jest filozofia w nauce?, in: Filozofia i wszechświat, 2006, 3-15.

[12] Henriques JB, Davidson RJ., Asymmetrical brain electrical activity discriminates between previously depressed subjects and healthy controls, in: Journal of Abnormal Psychology 99, 1990, 22-31.

[13] Henriques JB, Davidson RJ., Left frontal hypoactivation in depression, in: Journal of Abnormal Psychology 100, 1991, 535-545.

[14]Hohol M., Wyjaśnić umyst, Copernicus Center Press, Kraków, 2017.

[15] Hohwy, J., The predictive mind, Oxford University Press, New York, 2013.

[16]Husserl E., Formale und transzendentale Logik: Versuch einer Kritik der logischen Vernunft, Martinus Nijhoff, 1977, doi: 10.1007/978-94-010-1080-1.

[17]Jones M., Bradley C. L., Bayesian Fundamentalism or Enlightenment? On the explanatory status and theoretical contributions of Bayesian models of cognition, $w$ : Behavioral and Brain Sciences, 34 (04), 2011, 169-188. doi:10.1017/S0140525X10003134.

[18]Kahneman D., Tversky A., Judgment under Uncertainty: Heuristics and Biases, in: Science, New Series, Vol. 185, No. 4157, 1974, 1124-1131.

[19]Bazala M., Jędrychowska J., Kuźnicki J., Przeżyciowe badania nad funkcjonowaniem mózgu przy użyciu mikroskopii SPIM, in: Wszechświat, t. 117, nr 7-9/2016, 2016, 263269.

[20]Knill, D. C. \& Pouget, A., The Bayesian brain: the role of uncertainty in neural coding and computation, in: Trends Neuroscience 27, 2004, 712-719.

[21]Lakoff G., Johnson M., Metaphors we live by, University of Chicago Press, 2003.

[22] Lipton P., Inference to the Best Explanation, Routledge, London, 2008.

[23] Schreibman, S., Siemans, R., \& Unsworth, J., A Companion to Digital Humanities, Wiley-Blackwell, London, 2008.

[24] Sołoducha K., Życie $i$ wiedza. Georg Misch w poszukiwaniu postmetafizycznej metafizyki, Warszawa, 2007.

[25] Soon Ch.S., Braas M, Heinze H.J., Haynes J.D., Unconscious determinants of free decisions in the human brain, in: Nature Neuroscience 5, 2008, 543-545.

[26] Stacewicz P., Evolutionary Schema of Modeling Based on Genetic Algorithms, in: Studies in Logic, Grammar and Rhetoric 40 (53), 2015, 219-238.

[27] Stacewicz P., Wlodarczyk A., Modelling in the context of computer science - a methodological approach, in: Studies in Logic, Grammar and Rhetoric 20 (33), 2010, 155-179.

[28] Sutton SK, Davidson RJ., Resting prefrontal asymmetry: A biological substrate of the behavioral approach and behavioral inhibition system, in: Psychological Science 8, 1997, 204-210.

[29] Turner R., Computational Artifacts. Towards a Philosophy of Computer Science, Springer, 2018. 
[30] Wheeler RE, Davidson RJ, Tomarken AJ., Frontal brain asymmetry and emotional reactivity: A biological substrate of affective style. In: Psychophysiology 30, 1993, 8289.

[31]Wigner E.P., Niepojęta skuteczność matematyki w naukach przyrodniczych, in: Współczesna filozofia matematyki, red. R. Murawski, Wydawnictwo Naukowe PWN, Warszawa, 2002.

[32]Wilson M., Six views on embodied cognition, in: Psychonomic Bulletin \& Review, 2002, 625-636.

[33]Zajonc R., Attitudinal effects of mere exposure, in: Journal of Personality and Social Psychology, 9, part 2, 1968, 1-27.

[34]Zhao W., Chellaps R., Phillips P.J., Rosenfeld A., Face recognition. A literature survey, in: ACM Comput.Surv. 35(4), 2003, 399-458.

[35] http://www.braininitiative.org/achievements/brain-initiative-three-years-frontiersneuroscience/

[36] http://www.sprawdzamysondaze.pl/

Received 20.06.2018, Accepted 27.11.2018 